\title{
Do Langerhans cells play a role in vulvar epithelium resistance to squamous cell carcinoma?
}

\author{
Helena Rotsztejn ${ }^{1}$, Ewa Trznadel-Budźko² and Dorota Jesionek-Kupnicka ${ }^{3}$ \\ ${ }^{1}$ Section of Dermatology, Research Institute of the Polish Mother's Memorial Hospital, Łódź, Poland \\ ${ }^{2}$ Department of Dermatology and Pediatric Dermatology, Military-Medical Faculty, Medical University of Łódź, Poland \\ 3 Department of Tumor Pathology, Chair of Oncology, Medical University of Łódź, Poland
}

Received: 2006.04.27, Accepted: 2006.07.17, Published online first: 2007.03.20

\begin{abstract}
Introduction: Langerhans cells (LCs) are a very important part of the skin immune system.

Materials and Methods: Skin biopsies taken from 13 women after the removal of vulvar squamous cell carcinoma (SCC) who had not been treated earlier for any vulvar diseases were investigated. The control group consisted of 12 women who underwent a plastic surgical operation of the vulva region. Immunohistochemical staining was performed on formalin-fixed, paraffin-embedded tissues samples using antihuman CD1a antibody (NCL-CD1a-235, Novocastra).

Results: This study showed a large decrease in LCs in vulvar SCC.

Conclusions: It is postulated that the reduction in the number of LCs may be one of the reasons for a higher tendency of carcinogenesis in the vulvar region. Their role as a main element of the skin immune system in the initiation of this process needs further investigation. It is possible that research on LCs in the skin will cast a new light on their role and even contribute to the prophylaxis and treatment of skin and mucosa carcinomas.
\end{abstract}

Key words: vulva, Langerhans cells, squamous cell carcinoma.

Corresponding author: Helena Rotsztejn, Ph.D. M.D., Section of Dermatology, Research Institute of the Polish Mother’s Memorial Hospital, Rzgowska 281/284, 93-338 Łódź, Poland, tel.: +48 42 271-10-00, e-mail: rotsztejn@onet.eu

\section{INTRODUCTION}

Langerhans cells (LCs) constitute $3-8 \%$ of all epithelial cells. The largest number is found in the basal and squamous layers. They are not present in the corneous layer. LCs are dendritic cells and they specialize in antigen presentation [14, 16]. Researchers have recently turned their attention to the relationship between LCs and carcinoma transformations in the skin. In the past, LCs were determined by means of the reaction with S-100 antigen. It turned out that this antigen was also present on other cells, so the results of the examinations were not precise, and even contradictory $[1,13]$. At present, CD1a molecule and the positive reaction with the above-mentioned glycoprotein are basic to the evaluation of LCs [6]. Authors have also reported a diminishing and impairment of LC function as a result of immunosuppressive treatment, including applied locally corticosteroids and excessive UV radiation, especially UVB, which can subsequently lead to the development of skin carcinoma [15, 23]. It is proposed that LCs play a role in host resistance to malignant neoplasmas in the epidermis [8]. The aim of this study was to evaluate LCs in vulvar squamous cell carcinoma (SCC).

\section{MATERIALS AND METHODS}

The study group

We investigated skin biopsies taken from 13 women with vulvar SCC who had not been treated for any vulvar diseases earlier (mean age: 61.1 \pm 11.7 years). The patients underwent vulvectomy. The cases of SCC represented a well and moderate histopathological grade, with characteristic foci of keratinization. The adjacent tissues did not show pathological changes. The control group consisted of normal vulvar skin tissue obtained from surgical specimens from 12 women (mean age: 
$57.3 \pm 11.2$ ) who underwent a plastic surgical operation of the vulva region. The regional ethics committee approved the project. All enrolled subjects were informed about the purposes and methods of the research and gave their written consent.

\section{Immunohistochemistry}

Immunohistochemical staining was performed on formalin-fixed, paraffin-embedded tissues samples using antihuman CD1a antibody (NCL-CD1a-235, Novocastra). This antibody recognizes the human CD1a cell surface glycoprotein, a 43-49 kDa molecule expressed in association with $\beta 2$ microglobulin. CD1a is expressed strongly by cortical thymocytes, LCs in the epidermis, dendritic cells in dermis, and also by LCs of mucosa of the tonsil.

The paraffin-embedded sections of tumor were deparaffinized, rehydrated, and heat-treated for citrate microwave antigen retrieval in $10 \mathrm{mM}$ citrate buffer, $\mathrm{pH}$ 6.0 , at $350 \mathrm{~W}$ for $15 \mathrm{~min}$ and then cooled to room temperature. Sections were then blocked for peroxidases in $0.3 \% \mathrm{H}_{2} \mathrm{O}_{2}$ in methanol for $30 \mathrm{~min}$, and incubated with the primary antibody anti-CD1a (dilution 1:50) for 30 min at room temperature in a humidity chamber. For detection, a Dako Envision System HRP with DAB staining and hematoxylin counterstaining was used. For a negative control, the slides were stained with the omission of the primary antibody. For a positive control, tissues of mucosa of the tonsil were used.

\section{Evaluation of $L C S$}

Immunohistochemical staining revealed that LCs exhibited characteristic processes. The number of LCs in each of the cases was estimated as the number of cells calculated per 10 high-power fields (HPFs) at $400 \times$ magnification.

\section{Statistics}

The examined group and the control group were compared by the Mann-Whitney U-test.

\section{RESULTS}

Immunohistochemical staining revealed that LCs exhibited cytoplasmatic characteristic processes. The number of LCs in SCC was very low compared with the control group $(\mathrm{p}<0.001$; Table 1$)$, the mean number of LCs being 0.85/10 HPFs (range: 0.0-2.0; Fig. 1). The mean number of LCs in the control tissue was 11.58/10 HPFs (range: 6.0-15.0; Fig. 2).

\section{DISCUSSION}

This study suggests that the decreased number of LCs may be directly connected with the process of carcinogenesis in the vulvar regions. The vulvar mucosa can

Table 1. The number of Langerhans cells in squamous cell carcinoma and the control group

\begin{tabular}{lclcrcrc}
\hline Groups & Number & Range & Median & Mean & SD & SEM & p \\
\hline SCC & 13 & $0.0-2.0$ & 1.0 & 0.85 & 0.90 & 0.25 & $<0.001$ \\
Control & 12 & $6.0-15.0$ & 12.0 & 11.58 & 2.81 & 0.81 & \\
\hline
\end{tabular}

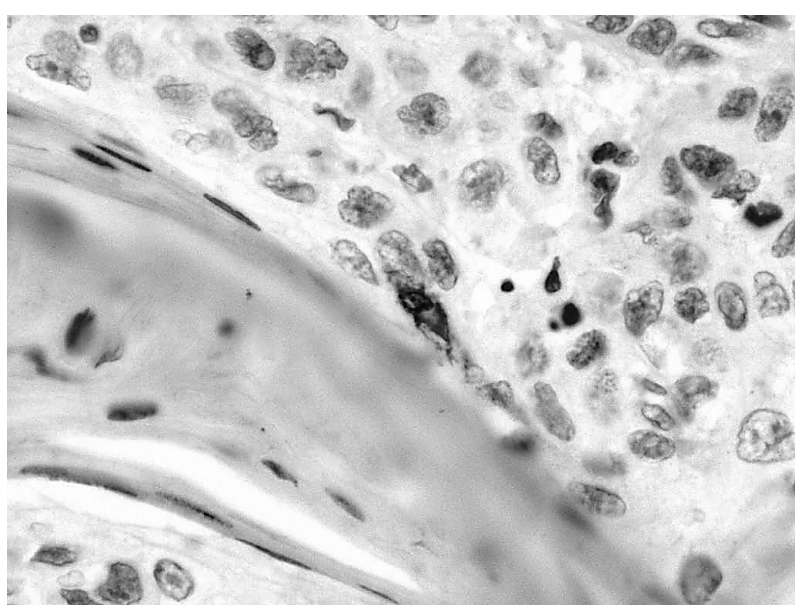

Fig. 1. The squamous cell carcinoma - the decreased number of Langerhans cells. Immunohistochemical staining with anti CD1a antibody, Dako Envision System HRP DAB, hematoxylin counterstaining, $\times 400$.

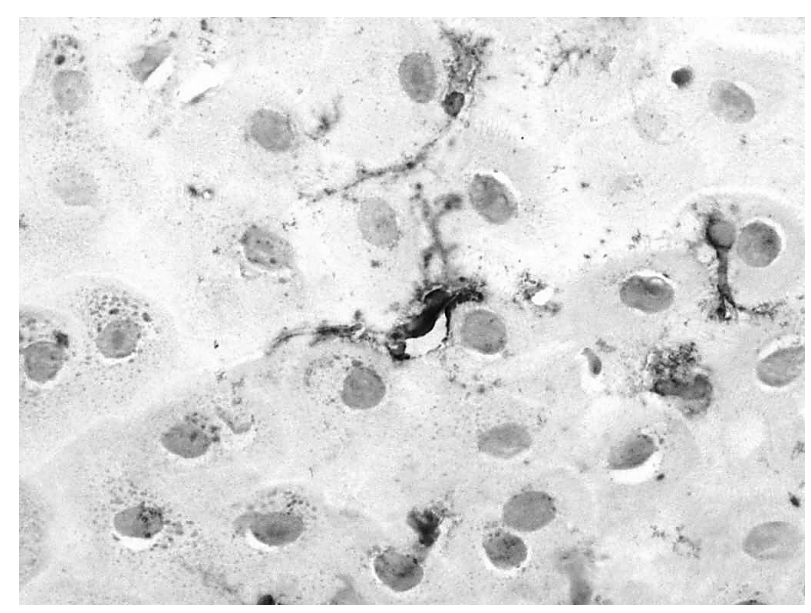

Fig. 2. The skin section of control tissue without pathological changes. Note a few LC with characteristic proccesses. Immunohistochemical staining with anti CD1a antibody, Dako Envision System HRP DAB, hematoxylin counterstaining, $\times 400$. 
be a starting point for SCC. In this region, carcinogenesis seems to be connected with infections and inflammation processes, which in turn may be caused by mechanical traumas (9). This may cause impairment of the skin's immune system, which can lead to carcinogenic transformation. Moreover, it is worth underlining that in vulvar lichen sclerosus, oxidative stress plays a significant role in involved tissue. Oxidative damage to lipids, DNA, and proteins may contribute to oxidative tissue injury, which may also lead to carcinogenesis [20]. Nitrative damage to nucleic acids also plays an important role in carcinogenesus. This occurs during inflammatory processes when reactive nitrogen species, such as peroxynitrite, nitroxyl, and nitrogen dioxide, are generated. This may lead to the accumulation of mutagenic DNA lesions and p53 in damaged epithelium and carcinoma connected with inflammation $[4,12]$.

The connection between inflammation and cancer caused by chronic infection has been recognized in numerous solid tumors. Helicobacter pylori-induced gastritis leading to gastric cancer, inflammatory bowel disease leading to colorectal cancer, inflammation in the pancreas, chronic viral hepatitis leading to liver cancer, and oral lichen planus leading to squamous oral cancer are among the examples $[4,5,7,12]$.

It is believed that vulvar SCC may be divided into two groups: a group originating from vulvar intraepithelial neoplasia, in which human papilloma virus (HPV) infection may cause carcinogenesis, and an SCC group which is connected with chronic vulvar dystrophy $[3,17]$. Various dystrophic lesions of the vulvar epithelium were found in about 70-80\% of SCC surrounding tissues [19].

Some authors also raise a question of the long-term application of steroid ointments in vulvar inflammation processes and the possibility of it leading to latent HPV infection. This may indicate that vulvar dystrophy is a process which can lead to carcinoma development. Other authors divide vulvar SCC into HPV-dependent and HPV-independent [6, 18, 21].

Many investigations have proved that UV radiation, especially UVB, has a similar influence on decreasing the LC number in the skin in a dose-dependent manner [22]. Interestingly, some studies also exhibited morphological changes of LCs (deformation of the dendritic processes and alterations of the Birbeck granules) [1, 24]. The immunosuppressive activity of UV radiation is caused by cytokines secreted by epithelial cells, mainly interleukin IL-10. This influences the skin's immune system through lowering the secretion of other cytokines and inhibiting antigen presentation by LCs. At the same time, IL-10 influences LCs, transforming them into inactive forms $[2,11]$.

In patients who underwent renal transplantation, impairment of the immune system function was connected with the development of skin carcinoma. An increased frequency of skin carcinoma, mainly SCC, was found in patients after renal transplantation subjected to immunosuppression [10].

Our findings clearly show a large decrease in or absence of LCs in vulvar SCC. The number of LCs was significantly decreased in the epidermis in Bowen's disease [6]. Investigations indicate a decrease in LC number in the epithelium of the inner surface of the prepuce, which, according to the researchers, together with infections and increased incidence of traumas in this region, may trigger carcinogenesis [25].

In SCC, very few CD1-positive LCs were concentrated at the periphery of neoplastic epithelium, while they were absent in the central part of the tumor [24].

The role of LCs as a main element of the skin's immune system in the initiation of the carcinogenic process needs further investigation. It is possible that research on LCs in the skin will cast a new light on their role and even contribute to the prophylaxis and treatment of skin and mucosa carcinomas.

\section{REFERENCES}

1. Alcalay J., Goldberg L. H., Wolf J. E. Jr. and Kripke M. L. (1989): Variations in the number and morphology of Langerhans' cells in the epidermal component of squamous cell carcinomas. Arch. Dermatol., 125, 917-920.

2. Asadullah K., Docke W. D., Sabat R., Ebeling W., Volk H. D. and Sterry W. (1999): Interleukin-10 in der Dermatologie. Hautartzt, 50, 12-19.

3. Carlson J. A., Ambros R., Malfetano J., Ross J., Grabowski R., Lamb P., Figge H. and Mihm M. C. Jr. (1998): Vulvar lichen sclerosus and squamous cell carcinoma: a cohort, case control, and investigational study with historical perspective; implications for chronic inflammation and sclerosis in the development of neoplasia. Hum. Pathol., 29, 932-948.

4. Chaiyarit P., Ma N., Hiraku Y., Pinlaor S., Yongvanit P., Jintakanon P., Murata M., Oikawa S. and Kawanish S. (2005): Nitrative and oxidative DNA damage in oral lichen planus in relation to human oral carcinogenesis. Cancer Sci., 96, 553-559.

5. Crowe S. E. (2005): Helicobacter infection, chronic inflammation, and the development of malignancy. Curr. Opin. Gastroenterol., 21, 32-38.

6. Duan H., Koga T., Masuda T., Mashino T., Imafuku S., Terao H., Murakami Y., Urabe K., Kiryu H. and Furue M. (2000): CD1a+, CD3+, CD4+, CD8+, CD68+ and cutaneous lymphocyte-associated antigen-positive cells in Bowen's disease. Br. J. Dermatol., 143, 1211-1216.

7. Farrow B. and Evers B. M. (2002): Inflammation and the development of pancreatic cancer. Surg. Oncol., 10, 153-169.

8. Fernandez-Bussy R., Cambazard F., Mauduit G. Schmitt D. and Thivolet J. (1983): T cell subsets and Langerhans cells in skin tumours. Eur. J. Cancer Clin. Oncol., 19, 907-913.

9. Fox H. and Wells M. (2003): Recent advances in the pathology of the vulva. Histopathology, 43, 209-216.

10. Galvao M. M., Sotto M. N., Kihara S. M. Rivitti E. A. and Sabbaga E. (1998): Lymphocyte subsets and Langerhans cells in sun-protected and sun exposed skin of immunosuppressed renal allograft recipients. J. Am. Acad. Dermatol., 38, 38-44.

11. Halliday G. M. and Le S. (2001): Transforming growth factor-beta produced by progressor tumors inhibits, while IL-10 produced by regressor tumors enhances, Langerhans cell migration from skin. Int. Immunol., 13, 1147-1154. 
12. Itzkowitz S. H. and Yio X. (2004): Inflammation and cancer IV. Colorectal cancer in inflammatory bowel disease: the role of inflammation. Am. J. Physiol. Gastrointest. Liver Physiol., 287, G7-17.

13. Kurihara K. and Hashimoto N. (1985): The pathological significance of Langerhans cells oral cancer. J. Oral Pathol., 14, 289-298.

14. Meunier L. (1996): Immune dendritic cells in human dermis. Eur. J. Dermatol., 6, 327-331.

15. Meunier L. (1999): Ultraviolet light and dendritic cells. Eur. J. Dermatol., 9, 269-275.

16. Nakagawa S. and Bost J. D. (2001): Role of Langerhans cells in the skin. What's new? J. Eur. Acad. Dermatol. Venerol., 15, 399-401.

17. Poulsen H., Junge J., Vyberg M., Horn T. and Lundvall F. (2003): Small vulvar squamous cell carcinomas and adjacent tissues. A morphologic study. APMIS, 111, 835-842.

18. Riethdorf S., Neffen E. F., Cviko A., Loning T., Crum C. P. and Riethdorf L. (2004): p16INK4A expression as biomarker for HPV 16-related vulvar neoplasia. Hum. Pathol., 35, 1477-1483.

19. Rouzier R., Morice P., Haie-Meder C., Lhomme C., Avril M. F., Duvillard P. and Castaigne D. (2001): Prognostic significance of epithelial disorders adjacent to invasive vulvar carcinomas. Gynecol. Oncol., 81, 414-419.

20. Sander C. S., Ali I., Dean D., Thiele J. J. and Wojnarowska F. (2004): Oxidative stress is implicated in the pathogenesis of lichen sclerosus. Br. J. Dermatol., 151, 627-635.

21. Scurry J. P. and Vanin K. (1997): Vulvar squamous cell carcinoma and lichen sclerosus. Australas. J. Dermatol., 38 (suppl. 1), 20-25.

22. Seite S., Zucchi H., Moyal D., Tison S., Compan D., Christiaens F., Gueniche A. and Fourtanier A. (2003): Alterations in human epidermal Langerhans cells by ultraviolet radiation: quantitative and morphological study. Br. J. Dermatol., 148, 291-299.

23. Tiplica G. S. (2001): Dermatocorticoterapie. Curtea Veche, Bukaresti, 20-21.

24. Townsend W. L., Gorrell M. D. and Mayer R. (1997): Langerhans cells in the development of skin cancer: a qualitative and quantitative comparison of cell markers in normal, acanthotic and neoplastic ovine skin. Pathology, 29, 42-50.

25. Weiss G. N., Sanders M. and Westbrook K. C. (1993): The distribution and density of langerhans cells in the human prepuce: site of a diminished immune response? Isr. J. Med. Sci., 29, 42-43. 